\title{
Risk reduction of contralateral breast cancer and survival after contralateral prophylactic mastectomy in BRCA / or BRCA2
} mutation carriers

\section{TC van Sprundel ${ }^{1,6}$, MK Schmidt ${ }^{2,3,6}$, MA Rookus ${ }^{3}$, R Brohet $^{3}$, CJ van Asperen ${ }^{4}$, EJTh Rutgers ${ }^{5}$, LJ van't Veer ${ }^{2}$ and RAEM Tollenaar*,1}

'Department of Surgery, D6-44, Leiden University Medical Center, PO Box 9600, 2300 RC Leiden, The Netherlands; ${ }^{2}$ Department of Pathology, The Netherlands Cancer Institute/Antoni van Leeuwenhoek Hospital, Amsterdam, The Netherlands; ${ }^{3}$ Department of Epidemiology, The Netherlands Cancer Institute/Antoni van Leeuwenhoek Hospital, Amsterdam, The Netherlands; ${ }^{4}$ Department of Clinical Genetics, Leiden University Medical Center, Leiden, The Netherlands; ${ }^{5}$ Department of Surgery, The Netherlands Cancer Institute/Antoni van Leeuwenhoek Hospital, Amsterdam, The Netherlands

The clinical outcome of contralateral prophylactic mastectomy (CPM) in women with a BRCA / or BRCA2 mutation and a personal history of invasive breast cancer is unknown. We identified a cohort of I 48 female BRCA / or BRCA2 mutation carriers (I I 5 and 33 , respectively) who previously were treated for unilateral invasive breast cancer stages I- IIla. In all, 79 women underwent a CPM, while the other women remained under intensive surveillance. The mean follow-up was 3.5 years and started at the time of CPM or at the date of mutation testing, whichever came last, that is, on average 5 years after diagnosis of the first breast cancer. One woman developed an invasive contralateral primary breast cancer after CPM, whereas six were observed in the surveillance group $(P<0.00$ I $)$. Contralateral prophylactic mastectomy reduced the risk of contralateral breast cancer by $91 \%$, independent of the effect of bilateral prophylactic oophorectomy (BPO). At 5 years follow-up, overall survival was $94 \%$ for the CPM group vs $77 \%$ for the surveillance group $(P=0.03)$, but this was unexpectedly mostly due to higher mortality related with first breast cancer and ovarian cancer in the surveillance group. After adjustment for BPO in a multivariate Cox analysis, the CPM effect on overall survival was no longer significant. Our data show that CPM markedly reduces the risk of contralateral breast cancer among BRCAI or BRCA2 mutation carriers with a history of breast cancer. Longer follow-up is needed to study the impact of CPM on contralateral breast cancer-specific survival. The choice for CPM is highly correlated with that for BPO, while only BPO leads to a significant improvement in overall survival so far.

British Journal of Cancer (2005) 93, 287-292. doi:10.1038/sj.bjc.6602703 www.bjcancer.com

Published online 19 July 2005

(C) 2005 Cancer Research UK

Keywords: breast cancer; BRCA I; BRCA2; mastectomy; surgery; prevention

Women identified as carriers of a mutation in one of the breast and ovarian cancer-susceptibility genes BRCA1 or BRCA2 have strongly elevated risks of developing breast or ovarian cancer (Ford et al, 1998). A recent meta-analysis (Antoniou et al, 2003) including 22 studies, revealed an average cumulative risk of $65 \%$ for breast cancer and $39 \%$ for ovarian cancer in BRCA1 mutation carriers by age 70 years. The corresponding estimates for women with a mutation in BRCA2 were 45 and $11 \%$. Once diagnosed with breast cancer, these women are also at high risk of developing breast cancer in the contralateral breast. Early reports of The Breast Cancer Linkage Consortium estimated a contralateral breast cancer cumulative risk of $50-60 \%$ at age 70 years in $B R C A 1$ or BRCA2 mutation carriers (Easton et al, 1995; The Breast Cancer Linkage Consortium, 1999). Later studies estimated even higher incidences of contralateral breast cancer within the first 5 years of

\footnotetext{
*Correspondence: Dr RAEM Tollenaar; E-mail: r.a.e.m.tollenaar@lumc.nl ${ }^{6}$ These authors contributed equally to this work

Received 29 March 2005; revised 16 June 2005; accepted 20 June 2005; published online 19 July 2005
}

follow-up after the primary breast cancer: $12-33 \%$ among BRCA1 or BRCA2 mutation carriers $(2.4-6.5 \%$ per year) (Robson et al, 1998; Verhoog et al, 1998, 1999) as compared to a $0.4-1 \%$ per year for breast cancer patients in general (Fisher et al, 1984).

Owing to the elevated risks and fear of contralateral breast cancer, some women opt for contralateral prophylactic mastectomy (CPM). No studies to date exist on the efficacy of CPM in carriers of $B R C A 1$ or $B R C A 2$ mutations. Two retrospective studies have evaluated a heterogenic population of breast cancer patients with variable extent of family history and reported a reduction of contralateral breast cancer after CPM, but without improvement of overall survival in a follow-up period of 7-10 years (Peralta et al, 2000; McDonnell et al, 2001). A recent systematic review included three additional studies; however, these lacked a comparison group and/or follow-up was not standardised (Lostumbo et al, 2004). Therefore, in the present study, the efficacy of CPM was investigated in a group of women with pathogenic BRCA1 or $B R C A 2$ mutations and a personal history of unilateral invasive breast cancer. 


\section{PATIENTS AND METHODS}

\section{Identification of patients}

All patients identified until June 2003 as being a $B R C A 1$ or $B R C A 2$ mutation carrier, with previous history of unilateral, stage I-IIIa, invasive breast cancer, from The Netherlands Cancer Institute, Amsterdam $(n=101)$ and The Leiden University Medical Centre, Leiden $(n=47)$, were included. All women underwent surgery for their primary breast cancer, either breast-conserving surgery or mastectomy. In addition, all women were counselled and monitored at the Family Cancer Clinic and outpatient clinic at each institute. BRCA1 or BRCA2 mutation status was determined by direct mutation testing. Women with so-called unclassified variants were not included in this study. Data on mutation status, date of disclosure DNA test result, pathological features and treatment of the primary breast cancer as well as recurrence, bilateral (prophylactic) (salpingo-)oophorectomy status (BPO), other carcinomas, last date of follow-up and vital status were extracted from medical files, operation and pathology reports.

\section{Surgical techniques and surveillance}

CPM was defined as surgical removal of the opposite breast in a patient with previous unilateral invasive breast cancer, provided that no suspicion for cancer in the opposite breast was apparent by means of preoperative physical, radiological and, if applicable, pathological examination. In case of a CPM, either a skin sparing or a simple total mastectomy was performed. In women who previously had undergone breast-conserving therapy for their first breast cancer, a residual mastectomy procedure was carried out on the ipsilateral breast at the time of CPM. In all cases, the nipple-areolar complex was removed, while the pectoralis muscles were preserved, except its fascia. Axillary node dissection was not performed. However, in case of accidental removal of some superficial axillary lymph nodes, these were examined histologically. After CPM, women returned yearly for a physical examination.

All CPM breast specimens were postoperatively examined for lesions by experienced pathologists at each institution. Three ductal carcinomas in situ and one $3.2 \mathrm{~cm}$ large, invasive ductal carcinoma Bloom \& Richardson nuclear grade III were detected in the specimens obtained at the time of prophylactic mastectomy. Preoperative clinical or radiological assessment had not revealed abnormalities.

According to Dutch guidelines, women with a BRCA1 or BRCA2 mutation are enrolled in the surveillance-screening program from age 25 years. This is continued after a first breast cancer for remaining breast tissue and the opposite breast. Regular surveillance consisted of a monthly breast self-examination, semiannually clinical breast examination and yearly mammography.

\section{Statistical analysis}

We addressed two main questions, first whether risk of contralateral breast cancer was different between the surveillance and CPM group, and second whether (contralateral) breast cancer specific and overall survival differed between the groups. The start of follow-up and inclusion criteria for analysis were chosen such that the risk reduction of CPM for contralateral breast cancer would not be overestimated (Klaren et al, 2003). Hence, the start of follow-up was defined in the surveillance group as date of mutation testing and in the CPM group as date of mutation testing or CPM, whichever came last. In the surveillance group, mutation testing was always performed after diagnosis of the first breast cancer. In the CPM group, 15 patients were tested before diagnosis of their first breast cancer; however, by definition the date of CPM was taken as the start of follow-up. Only in 11 patients, the results of mutation analysis became available after their CPM.

In the contralateral breast cancer risk analysis, patients in the surveillance group who experienced contralateral breast cancer before the date of mutation testing $(n=26)$ were excluded, as well as four patients in the CPM group in whom in situ or invasive carcinoma was detected at the time of prophylactic mastectomy. Patient and treatment characteristics did not significantly differ between patients who were kept in the contralateral breast cancer risk analysis ( $n=118$ out of 148) and patients who were excluded $(n=30)$, except that the latter had received less often chemotherapy ( 13.3 vs $53.5 \%, P=0.001$ ), had lower stage ( 53.3 vs $27.9 \%$ stage I, $P=0.049$ ), were diagnosed in earlier years (median $1990 \mathrm{vs}$ $1994, P=0.001$ ) and had a longer delay between primary breast cancer and date of mutation analysis (9.3 vs 5.3 years, $P=0.003)$. The four patients excluded from the CPM group were all still alive. Of the 26 patients, 24 excluded from the surveillance group were still alive, one died of breast cancer and one died of ovarian cancer.

In the survival analysis, all patients, also the 26 patients with contralateral breast cancer before the date of testing, were included.

$\chi^{2}$ tests, one-way ANOVA, Mann-Whitney $U$-tests and $t$-tests were used to compare the patient characteristics. Kaplan-Meier curves with log-rank test and Cox's regression models were used to evaluate the incidence of contralateral breast cancer and overall or breast cancer-specific survival. In the Cox's regression models, time between first breast cancer and start of follow-up (to adjust for survival bias), year of diagnosis first breast cancer, age at mutation analysis, age at diagnosis first breast cancer, BPO, surgery (breastconserving surgery or mastectomy), chemotherapy, radiotherapy and stage of first breast cancer were evaluated as confounders. If the univariate estimate of the hazard ratio (HR) for CPM changed more than $10 \%$ if a potential confounder was added to the model, this factor was accepted as a confounder. A two-sided $P$-value of $<0.05$ was considered to indicate statistical significance. All analyses were performed using SPSS Release 10.07 (Chicago, IL, USA).

\section{RESULTS}

\section{Patient characteristics}

The clinicopathological characteristics of the 148 women at time of the primary breast cancer diagnosis are summarised in Table 1. Eventually, 79 women opted for a CPM and 69 women remained under close surveillance. The calendar year of first breast cancer diagnosis was significantly later in the CPM group than in the surveillance group, that is, 4 years.

The patient characteristics at the time of CPM and of women under surveillance are listed in Table 2. The gene mutations in $B R C A 1$ or $B R C A 2$ were equally distributed between the two groups. The mean age at CPM was close to the mean age at mutation analysis for this group with an average interval between the first breast cancer diagnosis and CPM of 3.9 years, while women in the surveillance group were on average tested at an older age. Women with a CPM underwent more often an oophorectomy, especially if considering $\mathrm{BPO}$, and were significantly younger when they underwent this surgical intervention than women in the surveillance group. Considering the period from diagnosis of first breast cancer until the end of follow-up (10.5 years in the surveillance group $v s 7.4$ years in the CPM group), in the complete surveillance group 32 contralateral breast cancers were observed, as compared to only one in the CPM group (Table 3a). Recurrence of breast cancer did not differ between the CPM and surveillance group (Table 3a).

\section{Risk of contralateral breast cancer}

For the analyses of contralateral breast cancer, follow-up started at the date of mutation testing or the date of CPM, whatever came last 
Table I Clinicopathological characteristics of first breast cancer for women who opted for CPM and women under surveillance ${ }^{a}$

\begin{tabular}{|c|c|c|c|}
\hline Characteristic & $\begin{array}{l}\text { CPM group } \\
(N=79)\end{array}$ & $\begin{array}{c}\text { Surveillance } \\
\text { group } \\
(N=69)\end{array}$ & $P$-value \\
\hline \multicolumn{4}{|l|}{ Age at first breast cancer (years) } \\
\hline $\begin{array}{l}\text { Mean } \pm \text { s.e. } \\
\text { Range }\end{array}$ & $\begin{array}{c}38.0 \pm 0.9 \\
26-56\end{array}$ & $\begin{array}{c}39.4 \pm 1.0 \\
25-64\end{array}$ & 0.295 \\
\hline \multicolumn{4}{|l|}{ Year of diagnosis } \\
\hline Mean & 1995 & 1991 & $<0.001$ \\
\hline Median & 1997 & 1993 & \\
\hline Range & 1982-2002 & $1972-2002$ & \\
\hline \multicolumn{4}{|l|}{ Breast cancer stage } \\
\hline Stage I & $32(40.5)$ & $25(36.2)$ & 0.324 \\
\hline Stage Ila & $31(39.2)$ & $27(39.1)$ & \\
\hline Stage Ilb & $10(12.7)$ & $15(21.7)$ & \\
\hline Stage IIla & $6(7.6)$ & $2(2.9)$ & \\
\hline \multicolumn{4}{|l|}{ Pathological T stage $(\mathrm{cm})$} \\
\hline $\mathrm{TI}: \leqslant 2$ & $43(54.4)$ & $38(55.1)$ & 0.677 \\
\hline T2: $2-5$ & $33(41.8)$ & $30(43.5)$ & \\
\hline T3: >5 & $3(3.8)$ & I (I.4) & \\
\hline \multicolumn{4}{|l|}{ Axillary status } \\
\hline Node negative & $52(65.8)$ & $40(58.0)$ & 0.495 \\
\hline Node positive & $27(34.2)$ & $29(42.0)$ & \\
\hline \multicolumn{4}{|l|}{ Bloom \& Richardson grade } \\
\hline Grade 1 & $-(0.0)$ & | (2.1) & 0.481 \\
\hline Grade II & $22(32.4)$ & $16(33.3)$ & \\
\hline Grade III & $46(67.6)$ & $31(64.6)$ & \\
\hline \multicolumn{4}{|l|}{ Morphology } \\
\hline Ductal & $68(89.5)$ & $49(75.4)$ & 0.042 \\
\hline Other & $8(11.5)$ & $16(24.6)$ & \\
\hline \multicolumn{4}{|l|}{ Estrogen receptor status } \\
\hline Positive & $15(26.3)$ & $17(44.7)$ & 0.078 \\
\hline Negative & $42(73.7)$ & $21(55.3)$ & \\
\hline \multicolumn{4}{|l|}{ Progesterone receptor status } \\
\hline Positive & $12(22.6)$ & $12(33.3)$ & 0.332 \\
\hline Negative & $41(77.4)$ & $24(66.7)$ & \\
\hline \multicolumn{4}{|l|}{ Therapy } \\
\hline Breast-conserving surgery & $21(26.6)$ & $4 \mid(59.4)$ & $<0.001$ \\
\hline Radiotherapy & $46(58.2)$ & $58(84.1)$ & 0.001 \\
\hline Chemotherapy & $46(58.2)$ & $26(37.7)$ & 0.014 \\
\hline Hormonal therapy & $15(19.0)$ & $4(5.8)$ & 0.025 \\
\hline
\end{tabular}

$\mathrm{CPM}=$ contralateral prophylactic mastectomy; s.e. $=$ standard error of the mean. ${ }^{a}$ Values represent $N(\%)$, unless stated otherwise.

(see also Statistical analysis). The mean follow-up did not differ markedly between both groups, 3.4 vs 3.1 years, respectively (Table $3 \mathrm{~b})$. Six women (14\%) in the surveillance group developed contralateral breast cancer after a mean of 2.2 years follow-up (mean interval $9.0 \pm 6.2$ years after the first breast cancer diagnosis). The one case of contralateral breast cancer observed in the CPM group occurred in a 62-year-old woman 1.6 years after the start of follow-up, and 5.4 years after the first breast cancer diagnosis. A $1.8 \mathrm{~cm}$ large, invasive ductal carcinoma grade III (Bloom \& Richardson) was detected in minimal residual mammary gland tissue. At the end of the follow-up period, this woman was still alive and had no evidence of disease.

The contralateral breast cancer-free survival in the CPM group was significantly lower as compared to the women under surveillance (log rank, $P=0.006$ ) (Figure 1). Cox's proportionalhazards analysis showed that CPM significantly $(P=0.028)$
Table 2 Characteristics of women who opted for CPM and women under surveillance

\begin{tabular}{|c|c|c|c|}
\hline Characteristic & $\begin{array}{l}\text { CPM group } \\
(N=79)\end{array}$ & $\begin{array}{c}\text { Surveillance } \\
\text { group } \\
(\mathbf{N}=69)\end{array}$ & $P$-value \\
\hline $\begin{array}{l}\text { Mutation status, } N(\%) \\
\text { BRCAI } \\
\text { BRCA2 }\end{array}$ & $\begin{array}{l}60(75.9) \\
19(24.1)\end{array}$ & $\begin{array}{l}55(79.7) \\
14(20.3)\end{array}$ & 0.693 \\
\hline $\begin{array}{l}\text { Age at mutation analysis (years) } \\
\text { Mean } \pm \text { s.e. } \\
\text { Range }\end{array}$ & $\begin{array}{l}41.5 \pm 0.9 \\
27-61\end{array}$ & $\begin{array}{l}46.7 \pm 1.1 \\
26-76\end{array}$ & $<0.001$ \\
\hline $\begin{array}{l}\text { Age at CPM (years) } \\
\text { Mean } \pm \text { s.e. } \\
\text { Range }\end{array}$ & $\begin{array}{l}41.9 \pm 0.9 \\
27-61\end{array}$ & $\begin{array}{l}\text { NA } \\
\text { NA }\end{array}$ & \\
\hline $\begin{array}{l}\text { Bilateral (salpingo- } \\
\text { )oophorectomy, N (\%) } \\
\text { Indication } \\
\text { Prophylactic } \\
\text { Ovarian carcinoma } \\
\text { Metastasis breast cancer in } \\
\text { ovary } \\
\text { Adjuvant treatment first } \\
\text { breast cancer } \\
\text { Radiologic castration }\end{array}$ & $\begin{array}{c}61(96.8) \\
2(3.2) \\
-(0.0) \\
-(0.0) \\
-(0.0)\end{array}$ & $\begin{array}{c}39(84.8) \\
4(8.7) \\
\text { I }(2.2) \\
\text { I }(2.2) \\
\text { I }(2.2)\end{array}$ & $0.009^{a}$ \\
\hline $\begin{array}{l}\text { Age at bilateral prophylactic (salpi } \\
\text { Mean } \pm \text { s.e. } \\
\text { Range }\end{array}$ & $\begin{array}{l}\text { go-)oophorecto } \\
43.3 \pm 0.8 \\
30-60\end{array}$ & $\begin{array}{l}\text { (years) } \\
47.1 \pm 1.2 \\
35-64\end{array}$ & 0.009 \\
\hline $\begin{array}{l}\text { Ipsilateral mastectomy (before } \\
\text { or at the start of follow-up) }\end{array}$ & $79(100)$ & $34(49.3)$ & $<0.001$ \\
\hline
\end{tabular}

$\mathrm{CPM}=$ contralateral prophylactic mastectomy; s.e. $=$ standard error of the mean; $\mathrm{NA}=$ not applicable. ${ }^{\mathrm{a}}$ Comparing prophylactic only.

Table 3a Outcome after first breast cancer in all patients in the CPM and surveillance group

\begin{tabular}{|c|c|c|c|}
\hline Outcome & $\begin{array}{l}\text { CPM group } \\
(N=79)\end{array}$ & $\begin{array}{c}\text { Surveillance } \\
\text { group } \\
(N=69)\end{array}$ & $P$-value \\
\hline $\begin{array}{l}\text { Follow up after first breast cancer } \\
\text { mean } \pm \text { s.e. (years) }\end{array}$ & $7.4 \pm 0.5$ & $10.5 \pm 0.7$ & 0.035 \\
\hline \multicolumn{4}{|l|}{ Contralateral breast cancer } \\
\hline$N(\%)$ & $\mathrm{I}^{\mathrm{a}}(1.3)$ & $32(46.4)$ & $<0.001$ \\
\hline Time until occurrence (years) & 5.4 & $6.4 \pm 0.8$ & \\
\hline \multicolumn{4}{|l|}{ Vital status, $N(\%)$} \\
\hline Alive, disease free & $73(92.4)$ & $50(72.5)$ & \\
\hline Alive, breast cancer & I (I.3) & $7(10.1)$ & \\
\hline Alive, ovarian cancer & $2(2.5)$ & I (1.4) & \\
\hline Deceased from breast cancer & $3(3.8)$ & $8(11.6)$ & \\
\hline Deceased from ovarian cancer & $-(0.0)$ & $2(2.9)$ & \\
\hline Deceased from other cancer & $-(0.0)$ & I (1.4) & \\
\hline \multicolumn{4}{|l|}{ Recurrence, N (\%) } \\
\hline Local recurrence & $8(10.1)$ & $12(17.4)$ & 0.233 \\
\hline Regional recurrence & I (1.3) & I (1.4) & 1.000 \\
\hline Distant metastasis & $5(6.3)$ & $9(13.0)$ & 0.260 \\
\hline $\begin{array}{l}\text { Interval between primary breast } \\
\text { carcinoma and start of follow-up } \\
\text { (Tables } 3 b \text { and } c \text { ) }\end{array}$ & $4.0 \pm 0.5$ & $6.8 \pm 0.7$ & 0.001 \\
\hline
\end{tabular}

CPM = contralateral prophylactic mastectomy; s.e. $=$ standard error of the mean. ${ }^{a}$ Three ductal carcinoma in situ and one invasive breast cancers found after histological examination in the CPM were excluded. 
Table 3b Contralateral breast cancer incidence after the start of followup, which is at the date of mutation testing or date of CPM

\begin{tabular}{lccc}
\hline Outcome and follow-up & $\begin{array}{c}\text { CPM group } \\
(\mathbf{N}=\mathbf{7 5})\end{array}$ & $\begin{array}{c}\text { Surveillance } \\
\text { group } \\
(\mathbf{N}=\mathbf{4 3})\end{array}$ & P-value \\
\hline $\begin{array}{l}\text { Follow-up mean } \pm \text { s.e. (years) } \\
\text { Until contralateral breast } \\
\text { cancer, death or end of } \\
\text { follow-up }\end{array}$ & $3.4 \pm 0.2$ & $3.1 \pm 0.3$ & 0.440 \\
$\begin{array}{l}\text { Contralateral breast cancer } \\
\begin{array}{l}N(\%) \\
\text { Time until occurrence (years) }\end{array}\end{array}$ & $\mathrm{I}^{\mathrm{a}}(1.3)$ & $6^{\mathrm{b}}(14)$ & \\
\hline
\end{tabular}

$\mathrm{CPM}=$ contralateral prophylactic mastectomy; s.e. $=$ standard error of the mean aThree ductal carcinoma in situ and one invasive breast cancers found after histological examination in the CPM were excluded. ${ }^{b}$ Contralateral breast cancers that occurred before the date of mutation testing $(n=26)$ were excluded.

decreased the risk of contralateral breast cancer (HR $0.09(95 \%$ confidence interval (CI), 0.01-0.78)) (Table 4). Also within the group of women with a BPO, the risk of contralateral breast cancer was decreased after a CPM (3 vs 1 contralateral breast cancer in 39 women under surveillance and 61 women with CPM, respectively).

\section{Breast cancer-specific and overall survival}

In order to examine whether CPM prevented death from breast cancer, breast cancer-specific and overall survival were compared between the CPM and the surveillance group. The mean follow-up did not differ markedly between both groups, 3.4 vs 3.7 years, respectively (Table 3c). Most women in both groups died of breast cancer (Table $3 \mathrm{a}$ and $\mathrm{c}$ ). Breast cancer-specific survival (including the first breast cancers) was not significantly better in the CPM group (log rank, $P=0.11$ ) (Figure 2). However, these were mostly related to the first breast cancer as only one of them (in the surveillance group) had developed a contralateral breast cancer. Therefore, it was not possible to evaluate contralateral breast cancer-specific survival. A significant overall survival advantage was observed in the CPM group compared to the surveillance group ( $\log$ rank, $P=0.027$ ) (Figure 3 ) due to three additional events: two ovarian and one lung cancer. Multivariate Cox's proportional-hazards analysis showed that, after adjustment for BPO (and time between first breast cancer and start follow-up and chemotherapy treatment), women in the CPM group did not significantly have better survival than those under surveillance (overall mortality HR $0.35, P=0.14$ ) (Table 4). Patients who underwent BPO had significantly better breast cancer specific (HR 0.15 (95\% CI $0.04-0.51), P=0.003$ ) and overall survival (HR 0.14 (95\% CI $0.05-0.41), P<0.0001$ ) than patients who did not undergo BPO. In multivariate analysis, with adjustment for CPM, time between first breast cancer between first breast cancer and start follow-up and chemotherapy, the breast cancer-specific survival was no longer significant (HR 0.28 (95\% CI 0.07-1.11), $P=0.07$ ), while the impact of BPO on overall survival remained (HR 0.23 (95\% CI $0.07-0.78), P=0.018$ ). Having opted for both CPM and a $\mathrm{BPO}$ resulted in a significantly better survival than surveillance only (overall mortality HR $0.12(0.03-0.46)$ and breast cancerspecific mortality HR $0.16(0.04-0.61)$, both adjusted for time between first breast cancer and start follow-up and chemotherapy).

\section{DISCUSSION}

Women with a BRCA1 or BRCA2 mutation and a personal history of breast cancer have high risks of developing contralateral breast

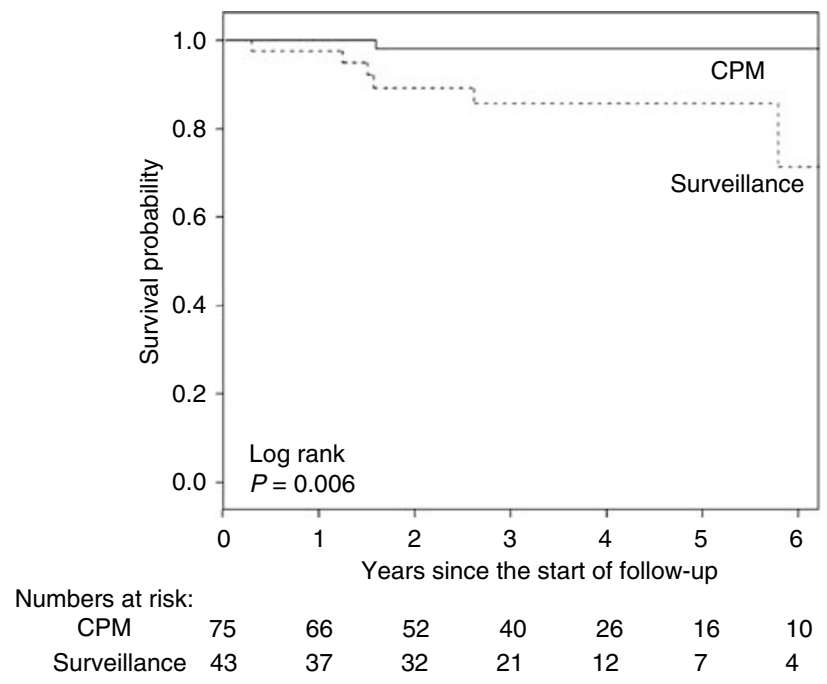

Figure I Contralateral breast cancer-free survival in patients who opted for CPM vs patients who remained under surveillance.

Table 3c Vital status after the start of follow-up, which is at the date of mutation testing or the date of CPM

\begin{tabular}{|c|c|c|c|}
\hline Outcome and follow-up & $\begin{array}{l}\text { CPM group } \\
(N=79)\end{array}$ & $\begin{array}{c}\text { Surveillance } \\
\text { group } \\
(N=69)\end{array}$ & $P$-value \\
\hline \multicolumn{4}{|l|}{ Follow-up mean \pm s.e. (years) } \\
\hline Until death or end of follow-up & $3.4 \pm 0.2$ & $3.7 \pm 0.2$ & 0.337 \\
\hline $\begin{array}{l}\text { Vital status, } N(\%) \text { (sum of } \\
\text { Table } 3 a \text { ) }\end{array}$ & & & 0.021 \\
\hline Alive & $76(96.2)$ & $58(84.1)$ & \\
\hline Deceased & $3(3.8)$ & II (I5.9) & \\
\hline
\end{tabular}

CPM = contralateral prophylactic mastectomy; s.e. $=$ standard error of the mean.

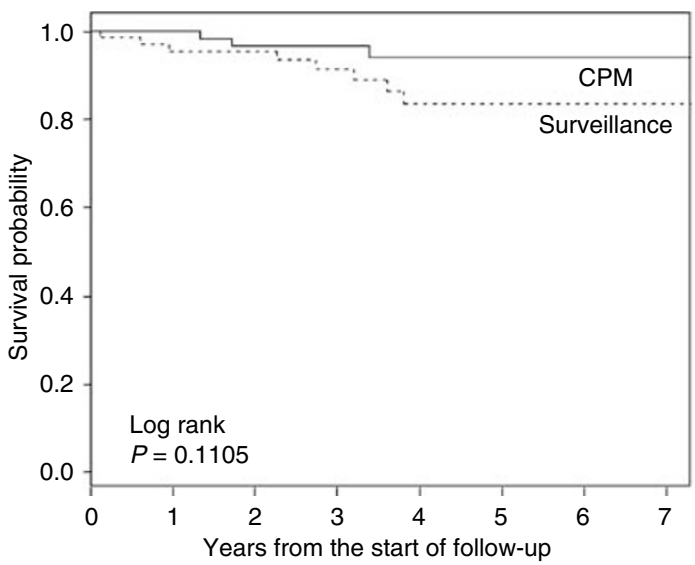

Numbers at risk:

$\begin{array}{ccccccccc}\text { CPM } & 79 & 69 & 56 & 42 & 27 & 17 & 10 & 5 \\ \text { Surveillance } & 69 & 61 & 55 & 43 & 28 & 19 & 13 & 4\end{array}$

Figure 2 Breast cancer-specific survival in patients who opted for CPM vs patients who remained under surveillance.

cancer. In this study, CPM reduced the risk for contralateral breast cancer in $B R C A 1$ or BRCA2 mutation carriers by $91 \%$, independent of the impact of BPO. Unadjusted overall survival was better for the CPM group $v s$ the surveillance group, but this was 


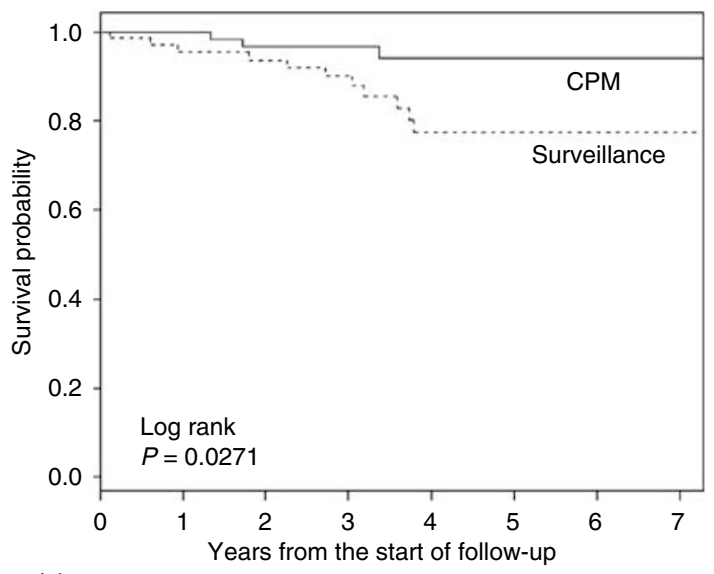

Numbers at risk:

$\begin{array}{ccccccccc}\text { CPM } & 79 & 69 & 56 & 42 & 27 & 17 & 10 & 5 \\ \text { Surveillance } & 69 & 61 & 55 & 43 & 28 & 19 & 13 & 4\end{array}$

Figure 3 Overall survival in patients who opted for CPM vs patients who remained under surveillance.

unexpectedly mostly due to the first breast cancer or other cancer-related events. In addition, after adjustment for BPO in a multivariate Cox analysis, the CPM effect was no longer significant.

The observed impact of CPM on contralateral breast cancer reduction is in agreement with studies on familial breast cancer. McDonnell et al (2001) studied the efficacy of CPM in 745 women, of whom 388 were premenopausal. They estimated a $90 \%$ reduction after a median follow-up, from the date of CPM, of 10 years by using the Anderson model (Anderson and Badzioch, $1985)$ to predict contralateral breast cancer risk. Peralta et al (2000) reported three contralateral breast cancers at the time of prophylactic mastectomy in 64 women who underwent a CPM. No other cases of contralateral breast cancer were observed after a median follow-up, from the date of first breast cancer, of 6.2 years, whereas 36 contralateral breast cancers occurred among 182 agematched controls after a median follow-up of 6.8 years. Despite a significant improved disease-free survival (defined as the time to any breast cancer event, whether recurrence or second primary), these authors also could not observe an improved overall survival, even though neither study adjusted for BPO status.

Bilateral prophylactic oophorectomy reduces the risk of first breast cancer by approximately $50 \%$ and the risk of ovarian cancer by almost 95\% (Kauff et al, 2002; Rebbeck et al, 2002). In our study, more women in the CPM group than in the surveillance group had undergone BPO. Bilateral prophylactic oophorectomy proved not to be a confounder in the contralateral breast cancer risk analysis (Table 4); however, it was a strong confounder in the survival analysis and clearly contributed to the difference in survival between the CPM and surveillance group. In addition, the impact of having opted for both CPM and a BPO vs surveillance resulted in a larger survival benefit than having opted for CPM or BPO alone.

Retrospective cohort studies considering breast cancer survival in $B R C A 1$ or $B R C A 2$ mutation carriers may suffer from ascertainment and testing bias. An ideal study design to evaluate the efficacy of CPM would be a prospective, randomised clinical trial, but such a trial is not feasible due to obvious ethical considerations. In this retrospective study, we tried to avoid overestimation of impact of the prophylactic procedure by testing and survival bias, by starting the follow-up at the date of positive DNA test result or date of CPM. By doing this, we excluded women from the surveillance group who were triggered to be tested by their diagnosis of contralateral breast cancer, precluding an overestimation of impact of the CPM (Klaren et al, 2003).

In the survival analyses, all patients were included, also the possibly oversampled cases with contralateral breast cancer, because they were still at risk at the date of testing. Their inclusion might have resulted in a spuriously elevated breast cancer-specific mortality. In our study, only two women who developed contralateral breast cancer in the surveillance group died so far. Therefore, we did not show an impact of CPM on survival in the total cohort nor in the smaller cohort $(n=118)$ (overall survival in CPM vs surveillance: 94 vs $68 \%, P=0.0072$; adjusted HR $0.31(95 \%$ CI, $0.07-1.38)$ ).

Despite the bias adjustment described, some differences between the groups remained: the CPM patients tended to come from families with a more severe familial breast cancer history (data not shown), were tested at a younger age and were tested more often close to their first breast cancer diagnosis. The latter can partly be logically explained because at average their breast cancer diagnosis was in a later calendar period when testing was more widely available already. In addition, patients coming from a family with a more severe breast cancer history may be more eager to get tested. However, these differences would lead to a higher background risk for contralateral breast cancer and worse survival in the CPM group and therefore might only strengthen our findings.

Even though stage did not differ between the groups, the CPM group seemingly had chosen, besides more BPO, for more aggressive therapy (chemotherapy, hormonal therapy and mastectomy) for their first breast cancer compared to the surveillance group. This difference in BPO and therapy might partly be explained by the fact that the patients in the CPM group were diagnosed in more recent calendar years and may partly be on initiative of women themselves, who may have higher fear of breast cancer because of their family history. The higher uptake of bilateral mastectomy by women with a positive family history has been supported by a study within a group of breast cancer patients with an uninformative BRCA test result (Schwartz et al, 2004). Although in our study women who opted for CPM had more often undergone ipsilateral mastectomy than those in the surveillance

Table 4 Risk of contralateral breast cancer and overall survival of women under surveillance compared to women who opted for CPM

\begin{tabular}{|c|c|c|c|c|c|c|}
\hline & \multicolumn{3}{|c|}{ Univariate } & \multicolumn{3}{|c|}{ Multivariate } \\
\hline $\begin{array}{l}\text { Risk of contralateral breas } \\
\text { CPM vs surveillance }\end{array}$ & 0.09 & $0.01-0.78$ & 0.03 & & & \\
\hline $\begin{array}{l}\text { Overall mortality } \\
\text { CPM versus surveillance }\end{array}$ & 0.26 & $0.07-0.94$ & 0.04 & $0.35^{d}$ & $0.09-1.39$ & 0.14 \\
\hline
\end{tabular}


group (73 vs 41\%), this did not have an impact on breast cancerspecific or overall survival (data not shown). Adjuvant chemotherapy has been associated with a decreased rate of contralateral breast cancer for breast cancer patients in general (Early Breast Cancer Trialists' Collaborative Group, 2001). In our study, however, neither chemotherapy nor mastectomy had confounding effects in the relation of CPM with contralateral breast cancer incidence. The low participation of tamoxifen use by the women in our study might be explained by their relatively young age as well as the year of their first breast cancer diagnosis, because the tamoxifen trials were mostly directed to postmenopausal women and the results published after the date at first breast cancer diagnosis in this population.

In summary, women with a BRCA1 or BRCA2 gene mutation and a history of unilateral invasive breast cancer are at increased risk for developing a primary contralateral breast cancer. This study shows that CPM significantly reduces the risk for contralateral cancer among BRCA1 or BRCA2 mutation carriers. In addition, after 5-year follow up, overall survival was better for the CPM group $v s$ the surveillance group $(P=0.03)$, but unexpectedly this was mainly due to the first breast cancer or other

\section{REFERENCES}

Anderson DE, Badzioch MD (1985) Bilaterality in familial breast cancer patients. Cancer 56: $2092-2098$

Antoniou A, Pharoah PD, Narod S, Risch HA, Eyfjord JE, Hopper JL, Loman N, Olsson H, Johannsson O, Borg A, Pasini B, Radice P, Manoukian S, Eccles DM, Tang N, Olah E, Anton-Culver H, Warner E, Lubinski J, Gronwald J, Gorski B, Tulinius H, Thorlacius S, Eerola H, Nevanlinna H, Syrjakoski K, Kallioniemi OP, Thompson D, Evans C, Peto J, Lalloo F, Evans DG, Easton DF (2003) Average risks of breast and ovarian cancer associated with $B R C A 1$ or $B R C A 2$ mutations detected in case series unselected for family history: a combined analysis of 22 studies. Am J Hum Genet 72: $1117-1130$

Early Breast Cancer Trialists' Collaborative Group (2001) Multi-agent chemotherapy for early breast cancer. Cochrane Database Syst Rev 4 CD000487.doi:10.1002/14651858.CD000487

Easton DF, Ford D, Bishop DT (1995) Breast and ovarian cancer incidence in BRCA1-mutation carriers. Breast Cancer Linkage Consortium. Am J Hum Genet 56: 265-271

Fisher ER, Sass R, Fisher B (1984) Pathologic findings from the National Surgical Adjuvant Project for Breast Cancers (protocol no. 4). X. Discriminants for tenth year treatment failure. Cancer 53: 712-723

Ford D, Easton DF, Stratton M, Narod S, Goldgar D, Devilee P, Bishop DT, Weber B, Lenoir G, Chang-Claude J, Sobol H, Teare MD, Struewing J, Arason A, Scherneck S, Peto J, Rebbeck TR, Tonin P, Neuhausen S, Barkardottir R, Eyfjord J, Lynch H, Ponder BA, Gayther SA, Zelada-Hedman M (1998) Genetic heterogeneity and penetrance analysis of the BRCA1 and BRCA2 genes in breast cancer families. The Breast Cancer Linkage Consortium. Am J Hum Genet 62: $676-689$

Kauff ND, Satagopan JM, Robson ME, Scheuer L, Hensley M, Hudis CA, Ellis NA, Boyd J, Borgen PI, Barakat RR, Norton L, Castiel M, Nafa K, Offit K (2002) Risk-reducing salpingo-oophorectomy in women with a BRCA1 or BRCA2 mutation. N Engl J Med 346: 1609-1615

Klaren H, Van't Veer L, van Leeuwen F, Rookus M (2003) Potential for bias in studies on efficacy of prophylactic surgery for BRCA1 and BRCA2 mutation. J Natl Cancer Inst 95: 941

Lostumbo L, Carbine N, Wallace J, Ezzo J (2004) Prophylactic mastectomy for the prevention of breast cancer. Cochrane Database Syst Rev 3, CD002748.pub2.doi:10.1002/14651858.CD002748.pub2 cancer-related events. After adjustment for BPO in a multivariate Cox analysis, the CPM effect was no longer significant. The choice for CPM is highly correlated with that for BPO, while only BPO leads to a significant improvement in overall survival so far. We do expect, considering the numbers of women with contralateral breast cancer in the surveillance group, that with longer follow-up $\mathrm{CPM}$ will be shown to improve contralateral breast cancer-specific survival. The choice for CPM must be seen within the context of other preventive measures in survival, such as BPO, tamoxifen use (Narod et al, 2000) and close surveillance.

\section{ACKNOWLEDGEMENTS}

This study was supported by a grant from the Breast Cancer Group of the European Organisation for Research and Treatment of Cancer (EORTC). We are indebted to HM Klaren and B Maertzdorf for their valuable help with recruiting data at the Netherlands Cancer Institute, and to $\mathrm{HH}$ Hartgrink for patients care at the surgical department at LUMC.
McDonnell SK, Schaid DJ, Myers JL, Grant CS, Donohue JH, Woods JE, Frost MH, Johnson JL, Sitta DL, Slezak JM, Crotty TB, Jenkins RB, Sellers TA, Hartmann LC (2001) Efficacy of contralateral prophylactic mastectomy in women with a personal and family history of breast cancer. J Clin Oncol 19: 3938-3943

Narod SA, Brunet JS, Ghadirian P, Robson M, Heimdal K, Neuhausen SL, Stoppa-Lyonnet D, Lerman C, Pasini B, los Rios P, Weber B, Lynch H (2000) Tamoxifen and risk of contralateral breast cancer in BRCA1 and BRCA2 mutation carriers: a case-control study. Hereditary Breast Cancer Clinical Study Group. Lancet 356: 1876-1881

Peralta E, Ellenhorn J, Wagman L, Dagis A, Andersen J, Chu D (2000) Contralateral prophylactic mastectomy improves the outcome of selected patients undergoing mastectomy for breast cancer. Am J Surg 180: 439445

Rebbeck TR, Lynch HT, Neuhausen SL, Narod SA, Van't Veer L, Garber JE, Evans G, Isaacs C, Daly MB, Matloff E, Olopade OI, Weber BL (2002) Prophylactic oophorectomy in carriers of $B R C A 1$ or $B R C A 2$ mutations. $N$ Engl J Med 346: 1616-1622

Robson M, Gilewski T, Haas B, Levin D, Borgen P, Rajan P, Hirschaut Y, Pressman P, Rosen PP, Lesser ML, Norton L, Offit K (1998) BRCAassociated breast cancer in young women. J Clin Oncol 16: $1642-1649$

Schwartz M, Lerman C, Brogan B, Peshkin B, Hughes Halbert C, DeMarco T, Lawrence W, Main D, Finch C, Magnant C, Pennanen M, Tsangaris T, Willey S, Isaacs C (2004) Impact of BRCA1/BRCA2 counseling and testing on newly diagnosed breast cancer patients. J Clin Oncol 22: 1823-1829

The Breast Cancer Linkage Consortium (1999) Cancer risks in BRCA2 mutation carriers. The Breast Cancer Linkage Consortium. J Natl Cancer Inst 91: $1310-1316$

Verhoog LC, Brekelmans CT, Seynaeve C, Dahmen G, van Geel AN, Bartels CC, Tilanus-Linthorst MM, Wagner A, Devilee P, Halley DJ, van den Ouweland AM, Meijers-Heijboer EJ, Klijn JG (1999) Survival in hereditary breast cancer associated with germline mutations of BRCA2. J Clin Oncol 17: 3396-3402

Verhoog LC, Brekelmans CT, Seynaeve C, van den Bosch LM, Dahmen G, van Geel AN, Tilanus-Linthorst MM, Bartels CC, Wagner A, van den Ouweland A, Devilee P, Meijers-Heijboer EJ, Klijn JG (1998) Survival and tumour characteristics of breast-cancer patients with germline mutations of BRCA1. Lancet 351: 316-321 